\title{
Application of Scoring System Components in Children Diagnosed with Tuberculosis in Jatinangor Primary Health Care, Sumedang
}

\author{
Mutiara Azhara Nurwanti, ${ }^{1}$ Chrysanti, ${ }^{2}$ Sri Sudarwati ${ }^{3}$ \\ ${ }^{1}$ Faculty of Medicine Universitas Padjadjaran, ${ }^{2}$ Department of Microbiology and Parasitology \\ Faculty of Medicine Universitas Padjadjaran, ${ }^{3}$ Department of Child Health Faculty of Medicine \\ Universitas Padjadjaran/Dr Hasan Sadikin General Hospital Bandung Indonesia
}

\begin{abstract}
Background: Diagnosis of tuberculosis in children is very difficult. Scoring system is used to diagnose tuberculosis in children in Indonesia. The aim of this study was to determine the application of scoring system components in children diagnosed with tuberculosis in the primary health care.

Methods: This cross-sectional study was conducted in Jatinangor Primary Health Care, Sumedang in September-October 2013. Data were obtained from 59 medical records of pediatric patients diagnosed with tuberculosis in 2010-2012, and recorded on the application of scoring system components including tuberculosis contact history, tuberculin skin test, fever, cough, nutritional status, lymph node enlargement, swelling of bones or joints, and chest X-ray.

Results: All scoring system components either with tuberculosis contact history, fever, cough, nutritional status, lymph node enlargement, swelling of bones or joints, and chest X-ray were performed on all of the children diagnosed with tuberculosis, except the tuberculin skin test was performed only on 38 (64\%) children. Most frequent clinical symptoms were cough (97\%), while fever and malnutrition occurred in $69 \%$ and $19 \%$ of children, respectively.

Conclusions: The application of scoring system components in children diagnosed with tuberculosis in Jatinangor primary health care is not having problems, except for the tuberculosis skin test. Most frequent clinical symptoms of childhood tuberculosis in this study are cough.
\end{abstract}

Keywords: Children diagnosed with tuberculosis, Jatinangor primary health care, scoring system

\section{Introduction}

In 1993, the World Health Organization (WHO) declared tuberculosis (TB) as a global public health emergency due to the increasing cases of TB and numerous patients who could not be healed. ${ }^{1}$ Based on the data from WHO, there were nearly 9 million new TB cases. Out of the 9 million TB cases each year, approximately 1 million $(11 \%)$ of cases occurred in children $\left(<15\right.$ years old). ${ }^{2}$ Indonesia ranks third in the category of countries with the greatest incidence of TB cases in the world after India and China. ${ }^{1}$ Based on The Current Situation, the Development of TB Report in Indonesia in January-June 2011 issued by the Directorate General of Disease Control and the Ministry of Health that referred to the Global Tuberculosis Control WHO Report, 2011, the proportion of childhood TB patients in 2011 was 1.7\%$17.2 \%$ with the lowest proportion found in Southeast Sulawesi and the highest in West Java. ${ }^{3}$

Diagnosing TB in children is very difficult, since childrenhave paucibacillary TB and are difficult in expectorate sputum useful for microbiological examination which is the gold standard for diagnosing TB. ${ }^{4}$ Therefore, the Respirology Unit in Coordination with Indonesian Pediatric Society (IDAI-Ikatan Dokter Anak Indonesia created guidelines for diagnosing TB using a scoring system. The criteria used in the scoring system are TB contact history, tuberculin skin test (TST), nutritional status, fever, cough, lymph nodes enlargement, swelling of the bones or joints, and chest X-ray. Children are diagnosed with TB if they get a score $\geq 6.1$ The scoring system used in the National TB Program is

Correspondence: Mutiara Azhara Nurwanti, Faculty of Medicine, Universitas Padjadjaran, Jalan Raya BandungSumedang Km.21, Jatinangor, Sumedang, Indonesia, Email: mutiaraazh@gmail.com 
implemented throughout the health service, including primary health care. However, the availability of laboratory equipment in primary health care is very limited. ${ }^{5}$ In fact, the use of the scoring system in primary health care requires a complete tool to fit the scoring system components to acquire a more accurate diagnosis and to avoid over diagnosis that cause overtreatment. Therefore, this study was conducted to determine the application of scoring system components in children diagnosed with TB in Jatinangor primary health care, Sumedang.

\section{Methods}

This cross-sectional study was conducted in Jatinangor primary health care, Sumedang in September-October 2013, using secondary data from medical records of pediatric patients who were diagnosed with TB at the Directly

Table 1 Characteristic of Study Subjects

\begin{tabular}{lc}
\hline \multicolumn{1}{c}{ Variable } & $\begin{array}{c}\mathbf{n = 5 9} \\
(\mathbf{\%})\end{array}$ \\
\hline Sex & \\
Male & $29(49)$ \\
Female & $30(51)$ \\
Age (years) & \\
$0-4$ & $24(41)$ \\
$5-9$ & $25(42)$ \\
10-14 & $10(17)$ \\
Region & \\
Cipacing & $12(20)$ \\
Hegarmanah & $8(13)$ \\
Jatiroke & $4(7)$ \\
Cikeruh & $7(12)$ \\
Cisempur & $2(3)$ \\
Sayang & $2(3)$ \\
Cibeusi & $9(15)$ \\
Cilayung & $2(3)$ \\
Mekar galih & $3(5)$ \\
Jatimukti & $2(3)$ \\
Cintamulya & $4(7)$ \\
Cileles & $1(2)$ \\
Others (outside Jatinangor) & $3(5)$ \\
\hline
\end{tabular}

Observed Treatment Short-Course (DOTS) Clinic in Jatinangor primary health care in 2010-2012. This study was conducted after obtaining approval from the Health Research Ethics Committee of the Regional Development Planning Agency, Department of Health, and Head of primary health care.

In this study, with a proportion of $17.2 \%$, confidence interval 95\%, and precision $10 \%$, the minimum sample required was 55 . Furthermore, the researcher assigned 80 study subjects. A total of 80 medical record data were obtained from medical records of 114 pediatric patients diagnosed with TB in the period 2010-2012 using the scoring system, to be sampled by a simple random sampling. Furthermore, out of 80 data, 21 data were excluded due to incomplete data about the use of the scoring system (referral patient from other health care). End total of the study subjects were 59 medical record data. From the 59 medical record data retrieved, data regarding the application of scoring system components included TB contact history, TST, fever, cough, nutritional status, lymph node enlargement, swelling of bones or joints, and chest X-ray. The 59 medical record data noted whether all components of the scoring system were examined and asked the patients, and then recorded the number of fulfillment of the value of each scoring system components. Afterward, data were analyzed using Microsoft Office Excel 2007.

\section{Results}

Furthermore, from 59 study subjects, the highest number of children was found in the age group 5-9 years (42\%). Study subjects were scattered throughout Jatinangor region, with the highest number found in Cipacing region (Table 1).

All components of scoring system were performed on all of children diagnosed with TB, either with TB contact history, malnutrition, fever, cough, lymph node enlargement, and swelling of bones or joints, and chest X-ray, except for the TST component. Most of the children had TB contact history (71\%). Out of the 38 children assessed for TST, $82 \%$ showed positive results. Almost all children (97\%) diagnosed with TB showed cough symptoms, and only $2 \%$ of children showed symptoms of swelling of bones or joints (Table 2).

Children are diagnosed with TB if they get a score $\geq 6$. Most of the children diagnosed with TB got score 6 (Figure). 
Table 2 Fulfillment of the Value of Each Scoring System Components

\section{Value scoring system components}

$\mathrm{n}=59(\%)$

TB contact history

Score 0: No contact

2: Family report, Acid Fast Bacilli negative, does not know, or does not clear

3: Family report, Acid Fast Bacilli positive

TST*

Score 0: Negative

3: Positive ( $\geq 10 \mathrm{~mm}$ or $\geq 5 \mathrm{~mm}$ on the state of immune suppression)

Nutritional status

Score 0: Normal

1: Below the red line (road to health card) or weight/age $<80 \%$

2: Clinical malnutrition (weight/age $<60 \%$ )

Fever without apparent cause

Score 0: No fever

1 : Fever $\geq 2$ weeks

Cough

Score 0: No cough

1: Cough $\geq 3$ weeks

Lymph nodes enlargement (coli, axilla, inguinal)

Score 0: No enlargement

1 : Enlargement $\geq 1 \mathrm{~cm}$, the amount $>1$, no pain

Swelling of the bones or joints (hip, knee, phalanges)

Score 0: No swelling

1 : There is swelling

Chest X-Ray

Score 0: Normal or not clear

1: suggestive TB

Note: * From 59 subjects, only 38 (64\%) subjects were examined TST

\section{Discussion}

In this study, children diagnosed with TB were greater in the age group 5-9 years (42.4\%). This result is in contrast to previous studies conducted by Wu et al. ${ }^{6}$ in China, Marais et al. ${ }^{7}$ in South Africa, and Lestari et al. ${ }^{8}$ in 6 provinces of Indonesia who stated that the prevalence of TB is more common in children $<5$ years old (39.5\%, 77.8\%, and 53\% respectively). Out of 25 children diagnosed TB in the age group 5-9 years, 23 children showed symptoms of cough. This might cause over diagnosed with cough-related asthma. Furthermore, a study conducted by Marais et al. ${ }^{9}$ showed the incidence of asthma increased in the age group 5-9 years, which has the samsymptom as TB namely cough $>2$ weeks.

One of the recommendations from WHO for diagnosing TB in children is to ask TB contact history. ${ }^{2}$ According to a study conducted by Iskandar et al. ${ }^{10}$, adults with Acid Fast Bacilli negative has the possibility to cause TB infections by $10 \%$ and is likely to cause TB disease by $16 \%$. In the study conducted by Singh et al. ${ }^{11}$, it concluded that the risk of childhood TB disease increases significantly $(77.8 \%)$ in children who have contact with Acid Fast Bacilli positive. However in this study, contact history with adults with Acid Fast 


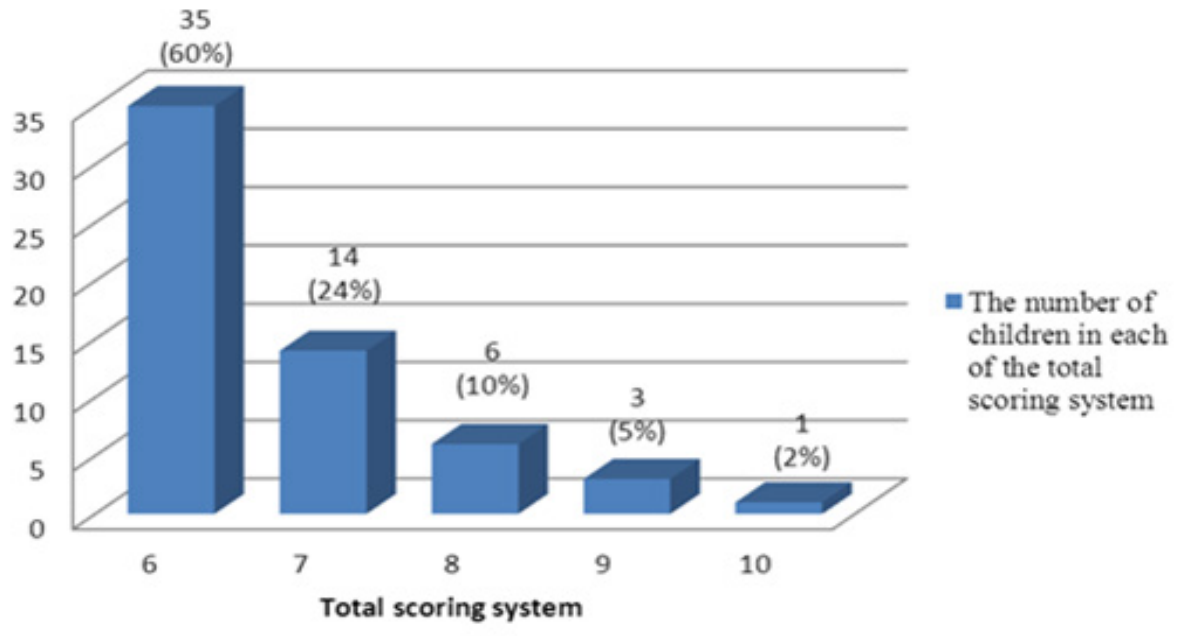

Figure Number of Children in Each of the Total Scoring System

Bacilli negative occurred in $44 \%$ of children diagnosed with TB, whereas a contact history with adults with Acid Fast Bacilli positive occurred in $27 \%$ of children. Dissimilarities occurred due to different study populations, the study by Iskandar et al. ${ }^{10}$ was conducted at Balai Kesehatan Paru Masyarakat (BKPM) Bandung, West Java on under-five children, and the study by Singh et al. ${ }^{11}$ was conducted in India on hospital-based under-five children.

The tuberculin skin test is one of the important tools for diagnosing TB in children. The positive result indicates that the patient has been infected by M. tuberculosis; therefore, to be used as a tool for diagnosing TB in children, it must be accompanied by clinical symptoms or other diagnostic criteria. Sensitivity and specificity of the TST is estimated to be 95 $\%{ }^{12}$ False-negative results may occur if the TST is performed at the beginning of infection, using inactive antigen (due to poor storage or inadequate administration), viral and bacterial infection, or because of immune suppresion. ${ }^{2}$ False-positive results can occur due to infection by nontuberculous mycobacteria, and BCG vaccination. ${ }^{2}$ Although TST is an important diagnostic tool, the provision of equipment and materials for the TST is still limited. As stated in the National Strategy for Controlling TB in Indonesia 2010-2014, many primary health care services lack laboratory facilities, both TST or chest X-ray, so that children are not examined with TST and chest X-ray. ${ }^{5}$ Hence in this study, $36 \%$ of children were not examined with TST. On the other hand, in this study most of the study subjects who were examined with TST, $82 \%$ showed positive TST, which was less than in the study conducted by Marais et al. ${ }^{7}$, which indicated that from all children diagnosed with TB, 94.4\% shows positive TST. This may occur due to the difference in study region and TST examiner.

Moreover, lymph nodes enlargement often occurs in childhood TB, due to the active response of lymph nodes and small pliable airways. ${ }^{13}$ Based on the study by Marais et al.14, the most common extra-thoracic TB is peripheral lymphadenitis with cervical lymph node enlargement which has the greatest occurrence. Lymph nodes enlargement is found in 58\% of children, and swelling of bones or joints occurred only in $2 \%$. This result is consistent with a study by Walakandou et al. ${ }^{15}$, who showed the most common clinical symptoms is lymph node enlargement and no one has shown swelling of bones.

In addition, chest X-ray is not the main diagnostic tool in childhood TB. Chest X-ray findings in childhood TB is highly variable including enlarged hilar or subcarinal lymph nodes, infiltrates, atelactasis, pleural effusion, and cavities parenchyma.12 However, the most common picture found in childhood TB is enlarged hilar or subcarinal lymph nodes because childhood TB is primary TB. ${ }^{2}$ Furthermore, Villiers et al. ${ }^{16}$ stated that the diagnosis of TB in children using chest X-ray have a sensitivity of $38.8 \%$ and a specificity of $74.4 \%$, in addition to the interpretation of chest X-ray which has a high subjectivity, so it is concluded that the chest X-ray is a weak indicator for diagnosing pulmonary $\mathrm{TB}$ in children. ${ }^{17}$ In this study, most of the study subjects (76\%) showed suggestive TB on chest 
X-ray, less than the study conducted by Marais et al. ${ }^{7}$ in South Africa, showing that all children diagnosed with TB disease show suggestive TB on chest X-ray. This may occur because of dissimilarities in the study population and the number of children diagnosed with TB.

One of the WHO recommendations which stated that to diagnose TB in children can be seen in the presence of any clinical symptoms, like chronic cough, fever, and weight loss. ${ }^{2}$ The incidence of cough and fever symptoms in this study was higher (97\% and 69\% respectively) than the crosssectional study by Marais et al. ${ }^{7}$ that showed symptoms of cough and fever appeared $44 \%$ and $22.2 \%$ of children respectively, and a study by Kruk et al. ${ }^{18}$ showed symptoms of cough and fever appeared 54.5\% and 18.2\% of children respectively. This may be due to over-diagnosed with cough-related asthma. Out of 21 children who were not examined with TST, 20 children showed symptoms of cough, seven children got TST negative, and all of the children showed symptoms of cough. Moreover, a study conducted by Marais et al. ${ }^{9}$ showed the proportion of asthma and TB in children $<13$ years old are $15.9 \%$ and $10.6 \%$ respectively, with the same symptom that is cough $>2$ weeks. Recurrent cough in asthma occurs only at night, while coughing in TB is a persistent cough that occurs day and night. Fever in TB is low-grade fever that occurs daily especially in the evening. While the weight loss is lower $(19 \%)$ compared to the results of the study by Marais et al. ${ }^{7}$ in 2005 (27.8\%).

Furthermore, the study conducted in South Africa in 2002 by Marais et al. ${ }^{7}$, compared the clinical symptoms in children without TB and children with TB in a high burden community which stated that the usual clinical symptoms suffered by the child is coughing, weight loss, fever, anorexia, fatigue, night sweats, and difficulty breathing. However, only the symptoms of weight loss, either alone or in combination with other clinical symptoms (cough), which are significantly more common clinical symptoms suffered by children with TB. A prospective study conducted by Marais et al. ${ }^{19}$ in the same country in 2003-2005 stated that the combination of a cough $\geq 2$ weeks, weight loss, and fatigue provides reasonable diagnostic accuracy with sensitivity $62.6 \%$ and specificity $89.8 \%$. In this study, the clinical symptoms which always occurred were either fever $\geq 2$ weeks, malnutrition, cough $\geq 3$ weeks, lymph nodes enlargement, or swelling of the bones or joints along with other components of the scoring system. Therefore, symptom- based screening should be considered to diagnose TB in children in resource-limited settings like primary health care.

Children are diagnosed with TB if they get a score $\geq 6$. In this study, most of the children diagnosed with TB $(60 \%)$ got score 6 . The maximum score in this study was 10 which was of one child (2\%). Unfortunately, researchers have not found a study showing the number of children in each of the total scoring system.

Besides in Indonesia, the scoring system is also used by other countries with different components. In the scoring system recommended by the Brazilian Ministry of Health $^{20}$, the components used are clinical symptoms of fever, cough, loss of energy, weight loss, night sweats $>2$ weeks, chest X-ray, history of contact with adult TB $<2$ years, BCG vaccination and TST, and nutritional status. In the scoring system of Indonesia, night sweats and BCG vaccination components are not included, besides the definition for history of contact is different.

This study was concerned with the symptom of cough which occurred on $97 \%$ of children. Therefore, suggestions for a further study on pediatric patients who showed clinical symptoms of coughing should be followed and evaluated as well as the disease progression until completion of treatment, including to detecting the possibility of overdiagnosis. Perhaps it is necessary to conduct training about how to diagnose TB in children for the primary health care staff.

The limitations of the study were, this study was conducted only in one area of primary health care and did not perform sensitivity and specificity testing since scoring system is the diagnostic tools. Hence, a further study needs to be conducted in larger regions of primary health care and examination of the sensitivity and specificity of scoring system.

In conclusion, the application of scoring system components in children diagnosed with TB in Jatinangor primary health care is not having problems, except for the TST. Most frequent clinical symptoms of TB in this study are cough.

\section{References}

1. Kementerian Kesehatan Republik Indonesia. Keputusan Menteri Kesehatan Republik Indonesia tentang pedoman penanggulangan tuberkulosis (TB). Jakarta: Kementerian Kesehatan Republik Indonesia; 2009.

2. World Health Organization (WHO). 
Guidance for national tuberculosis programmes on the management tuberculosis in children. Geneva, Switzerland: WHO; 2006.

3. Ditjen PP\&PL Kementrian Kesehatan RI. Laporan situasi terkini perkembangan tuberkulosis di Indonesia. Jakarta: Kementrian Kesehatan RI; 2011.

4. Marais BJ, Gie RP, Schaaf HS, Beyers N, Donald PR, Starke JR. Childhood pulmonary tuberculosis: old wisdom and new challenges. Am J Respir Crit Care Med. 2006;173(10):1078-90.

5. Kementrian Kesehatan Republik Indonesia. Strategi nasional pengendalian TB di Indonesia 2010-2014. Jakarta: Direktorat Jendral Pengendalian Penyakit dan Penyehatan Lingkungan, 2011.

6. Wu X-R, Yin Q-Q Jiao A-X, Xu B-P, Sun L, Jiao $W$-W, et al. Pediatric tuberculosis at Beijing Children's Hospital:2002-2010. Pediatrics. 2012;130:e1433-40.

7. Marais BJ, Obihara CC, Gie RP, Schaaf HS, Hesseling AC, Lombard C, et al. The prevalence of symptoms associated with pulmonary tuberculosis in randomly selected children from a high burden community. Arch Dis Child. 2005;90(11):1166-70.

8. Lestari T, Probandari A, Hurtig AK, Utarini A. High caseload of childhood tuberculosis in hospitals on Java Island, Indonesia: a cross sectional study. BMC public health. 2011;11:784.

9. Marais BJ, Gie RP, Obihara CC, Hesseling AC, Schaaf HS, Beyers N. Well defined symptoms are of value in the diagnosis of childhood pulmonary tuberculosis. Arch Dis Child. 2005;90(11):1162-5.

10. Iskandar H, Nataprawira HMD, Garna $\mathrm{H}$, Djais JTB. Tuberculosis prevalence among underfive children in household contact with negative acid fast bacilli adult pulmonary tuberculosis. Pediatrica Indonesiana. 2008;48:18-22.

11. Singh M, Mynak ML, Kumar L, Mathew JL,
Jindal SK. Prevalence and risk factors for transmission of infection among children in household contact with adults having pulmonary tuberculosis. Arch Dis Child. 2005;90(6):624-8.

12. Cruz AT, Starke JR. Pediatric tuberculosis. Pediatr Rev. 2010;31(1):13-25.

13. Britton P, Perez-Valez CM, Marais BJ. Diagnosis, treatment, and prevention of tuberculosis in children. NSW Public Health Bulletin. 2013;24(1):15-21.

14. Marais BJ, Gie RP, Schaaf HS, Hesseling AC, Enarson DA, Bayers N. The spectrum of disease in children treated for tuberculosis in a highly endemic area. Int J Tuberc Lung Dis. 2006;10(7):732-8.

15. Walakandou LR, Umboh A, Wahani A. The occurence and is factors of tuberculosos in children with close contact to adult lung tuberculosis. Pediatrica Indonesiana. 2010;50:233-38.

16. Marais BJ, Pai M. Recent advances in the diagnosis of childhood tuberculosis. Arch Dis Child. 2007;92(5):446-52.

17. Villiers RV, Andronikou S, Westhuizen SVD. Specificity and sensitivity of chest radiographs in the diagnosis of paediatric pulmonary tuberculosis and the value of additional high-kilovolt radiographs. Australas Radiol. 2004;48(2):148-53.

18. Kruk A, Gie RP, Schaaf HS, Marais BJ. Symptom-based screening of child tuberculosis contacts: improved feasibility in resource-limited settings. Pediatrics. 2008;121(6):e1646-52.

19. Marais BJ, Gie RP, Hesseling AC, Schaaf HS, Lombard C, Enarson Da, et al. A refined symptom-based approach to diagnose pulmonary tuberculosis in children. Pediatrics. 2006;118(5):e1350-9.

20. Sant'Anna CC, Santos MARC, Franco R. Diagnosis of pulmonary tuberculosis by score system in children and adolescents: a trial in a reference center on Bahia, Brazil. Braz J of Infect Dis. 2004;8(4):305-10. 